\title{
Tropospheric water vapour and relative humidity profiles from lidar and microwave radiometry
}

\author{
F. Navas-Guzmán ${ }^{1,2, *}$, J. Fernández-Gálvez ${ }^{1,2}$, M. J. Granados-Muñoz ${ }^{1,2}$, J. L. Guerrero-Rascado ${ }^{1,2}$, \\ J. A. Bravo-Aranda ${ }^{1,2}$, and L. Alados-Arboledas ${ }^{1,2}$ \\ ${ }^{1}$ Department of Applied Physics, University of Granada, Granada, 18071, Spain \\ ${ }^{2}$ Andalusian Institute for Earth System Research (IISTA), Av. del Mediterráneo s/n, 18006, Granada, Spain \\ *now at: Institute of Applied Physics (IAP), University of Bern, Bern, Switzerland
}

Correspondence to: F. Navas-Guzmán (fguzman@ugr.es)

Received: 29 September 2013 - Published in Atmos. Meas. Tech. Discuss.: 5 December 2013

Revised: 28 February 2014 - Accepted: 28 March 2014 - Published: 9 May 2014

\begin{abstract}
In this paper, we outline an iterative method to calibrate the water vapour mixing ratio profiles retrieved from Raman lidar measurements. Simultaneous and co-located radiosonde data are used for this purpose and the calibration results obtained during a radiosonde campaign in summer and autumn 2011 are presented. The water vapour profiles measured during night-time by the Raman lidar and radiosondes are compared and the differences between the methodologies are discussed. Then, a new approach to obtain relative humidity profiles by combination of simultaneous profiles of temperature (retrieved from a microwave radiometer) and water vapour mixing ratio (from a Raman lidar) is addressed. In the last part of this work, a statistical analysis of water vapour mixing ratio and relative humidity profiles obtained during 1 year of simultaneous measurements is presented.
\end{abstract}

\section{Introduction}

Water vapour is one of the most important constituents in the earth's atmosphere and it is characterized by high variability in space and time. It plays a key role in the global radiation budget and in energy transport mechanisms in the atmosphere (Whiteman et al., 1992; Ferrare et al., 2000) as well as in photochemical processes (Haefele et al., 2008). Moreover, it is the most important gaseous source of infrared opacity in the atmosphere, accounting for about $60 \%$ of the natural greenhouse effect for clear skies (Kiehl and Trenberth, 1997), providing the largest positive feedback in model projections of climate change (Held and Soden, 2000). It also contributes indirectly to the radiative budget by means of microphysical processes leading to the formation and development of clouds, and by affecting the size, shape and chemical composition of aerosol particles (Reichardt et al., 1996), thus modifying the role of aerosol in the radiative forcing (DeTomasi and Perrone, 2003).

To achieve a comprehensive understanding of the role of water vapour on local and global scales, systematic observations with high spatial and temporal resolution are required. Among the in situ techniques, radiosonde is extensively used due to its high spatial resolution, but the temporal resolution depends on the launch frequency. There are additional disadvantages: it is a costly technique, the verticality of the sounding depends on the wind regime and its changes with altitude (balloons drift with wind), and it is difficult to make accurate water vapour measurements in conditions of low relative humidity (Vaughan et al., 1988).

Other measurement techniques have become available to address the need for improved water vapour measurements. These techniques include satellite, microwave radiometry (Han et al., 1994; Scheiben et al., 2013), DIAL lidar (Ismail and Browell, 1994), sun and star photometers (Pérez-Ramírez et al., 2012) and Raman lidar (Whiteman et al., 1992; Mattis et al., 2002; Guerrero-Rascado et al., 2008). By virtue of its ability to provide both high spatial and temporal resolution measurements of water vapour throughout most of the troposphere, Raman lidar has emerged in the last decades as a powerful tool for providing detailed water vapour profiles as required for modelling the complicated processes aforementioned. 
This paper addresses the retrieval of tropospheric water vapour profiles combining different remote sensing techniques. Water vapour mixing ratio profiles $w(z)$ were obtained by means of Raman lidar measurements. The calibration of the lidar water vapour channel was performed by comparison with radiosonde measurements. The combination of $w(z)$ from lidar and temperature profiles $T(z)$ from microwave radiometer allowed obtaining relative humidity profiles.

The paper is organized as follows. In Sect. 2, the instrumentation and the experimental site are briefly described. Section 3 deals with the methodology applied to retrieve water vapour and relative humidity profiles, including details about the lidar calibration. A statistical analysis of water vapour and relative humidity is presented in Sect. 4. Finally conclusions are found in Sect. 5.

\section{Instrumentation and experimental site}

Lidar measurements were performed by means of a Raman lidar model LR331D400 (Raymetrics S.A., Greece). The system is configured in a monostatic biaxial alignment pointing vertically to the zenith. A Nd:YAG laser emits pulses at $1064 \mathrm{~nm}(110 \mathrm{~mJ}), 532 \mathrm{~nm}(65 \mathrm{~mJ})$ and $355 \mathrm{~nm}(60 \mathrm{~mJ})$ simultaneously, firing laser shots with a repetition rate of $10 \mathrm{~Hz}$. A $0.4 \mathrm{~m}$ diameter Cassegrain telescope collects radiation backscattered by atmospheric molecules and particles. The receiving subsystem also includes a wavelength separation unit with dichroic mirrors, interferential filters and a polarization cube. Detection is carried out in seven channels corresponding to elastic wavelengths at 1064, 532 (paralleland perpendicular-polarized) and $355 \mathrm{~nm}$, and to inelastic wavelengths at $607 \mathrm{~nm}$ (nitrogen Raman-shifted signal excited by radiation at $532 \mathrm{~nm}$ ), 387 (nitrogen Raman-shifted signal excited by radiation at $355 \mathrm{~nm}$ ) and $408 \mathrm{~nm}$ (water vapour Raman-shifted signal excited by radiation at $355 \mathrm{~nm}$ ). The instrument is operated with a vertical resolution of $7.5 \mathrm{~m}$. Due to the instrument setup, the incomplete overlap between the laser beam and the receiver field of view limits the lowest observations (Wandinger and Ansmann, 2002; Guerrero-Rascado et al., 2010; Navas-Guzmán et al., 2011). Correction of the overlap effect is performed by applying the procedure suggested by Wandinger and Ansmann (2002). The Raman lidar was incorporated to EARLINET (European Aerosol Research Lidar NETwork) (Bösenberg et al., 2003) in April 2005. It has taken part of the EARLINET ASOS (European Aerosol Research Lidar Network - Advanced Sustainable Observation System) project and currently is involved in the ACTRIS (Aerosols, Clouds, and Trace gases Research InfraStructure Network) European project. Further details in relation to this instrument can be found in Guerrero-Rascado et al. (2009).

Tropospheric temperature and humidity profiles were measured by a ground-based multifrequency passive microwave radiometer (RPG-HATPRO, Radiometer Physics $\mathrm{GmbH}$ ). This instrument performs measurements of the sky brightness temperature in a continuous and automated way with a radiometric resolution between 0.3 and $0.4 \mathrm{~K}$ root mean square error at $1.0 \mathrm{~s}$ integration time. The radiometer uses direct detection receivers within two bands: $22-31$ and $51-58 \mathrm{GHz}$. The first band contains channels providing information about the humidity profile of the troposphere, while the second band contains information about the temperature profile. The retrievals of both temperature and humidity profiles from brightness temperature are done by the inversion algorithms described in Rose et al. (2005). Temperature data are provided with $0.1 \mathrm{~K}$ precision and the accuracy of the temperature retrievals has a mean value of up to $0.8 \mathrm{~K}$ within the boundary layer. Tropospheric profiles are obtained from the surface up to $10 \mathrm{~km}$ using 39 heights with vertical resolution ranging from $10 \mathrm{~m}$ near the surface to $1000 \mathrm{~m}$ for altitudes higher than $7 \mathrm{~km}$. For heights below $3 \mathrm{~km}$ (a.s.l.), where the planetary boundary layer (PBL) is usually located over Granada (Granados-Muñoz et al., 2012), data at 25 points with resolution between 10 and $200 \mathrm{~m}$ are provided.

During summer and autumn 2011, radiosounding data were also available at the site. A total of 12 radiosoundings (six at midday and six at night) were launched with simultaneous measurements of the lidar system and the microwave radiometer. Radiosounding data were obtained using a GRAW DFM-06 radiosonde (GRAW Radiosondes, Germany), which is a lightweight weather radiosonde that provides temperature (resolution $0.01{ }^{\circ} \mathrm{C}$, accuracy $0.2^{\circ} \mathrm{C}$ ), pressure (resolution $0.1 \mathrm{hPa}$, accuracy $0.5 \mathrm{hPa}$ ), relative humidity (resolution $1 \%$, accuracy $2 \%$ ) and wind (accuracy $0.2 \mathrm{~m} \mathrm{~s}^{-1}$ ). Data acquisition and processing were performed by the Grawmet5 software and a GS-E ground station from the same manufacturer.

Data were collected at the Andalusian Centre for Environmental Research located in the city of Granada (Spain, $37.16^{\circ} \mathrm{N}, 3.6^{\circ} \mathrm{W}, 680 \mathrm{~m}$ above sea level (a.s.1.)). Granada is a non-industrialized and medium-size city surrounded by mountains, with a population of 240000 that increases up to 350000 if we include the wider metropolitan area. The city is situated in a natural basin surrounded by mountains with elevations between 1000 and 3500 ma.s.l. The study area is only about $200 \mathrm{~km}$ from the African continent and approximately $50 \mathrm{~km}$ from the western Mediterranean basin (Alados-Arboledas et al., 2011).

\section{Water vapour and relative humidity retrievals}

\subsection{Water vapour profile from Raman lidar measurements}

Lidar systems can be used to monitor the water vapour mixing ratio in the atmosphere. The method is based on the Raman effect. When a substance is subjected to an incident 
exciting wavelength, it can exhibit the Raman effect which consists of re-emitted secondary light at wavelengths that are shifted from the incident radiation. The magnitude of the shift is unique to the scattering molecule, while the intensity of the Raman band is proportional to the molecular number density. The water vapour Raman lidar technique uses the ratio of rotational-vibrational Raman scattering intensities from water vapour and nitrogen molecules, which is a direct measurement of the atmospheric water vapour mixing ratio. The lidar equation can be expressed for the nitrogen and water vapour Raman signals as follows:

$$
\begin{aligned}
P\left(R, \lambda_{i}\right) & =P\left(\lambda_{0}\right) K_{i} \frac{O_{i}(R)}{R^{2}} \beta\left(R, \lambda_{i}\right) \\
& \exp \left\{-\int_{0}^{R}\left[\alpha\left(r, \lambda_{0}\right)+\alpha\left(r, \lambda_{i}\right)\right] \mathrm{d} r\right\},
\end{aligned}
$$

where the index $i$ indicates the species nitrogen $\left(\mathrm{N}_{2}\right)$ or water vapour $\left(\mathrm{H}_{2} \mathrm{O}\right) . P\left(R, \lambda_{i}\right)$ is the backscattered laser power at the Raman-shifted wavelengths, from range $R$; $P\left(\lambda_{0}\right)$ is the emitted laser power at wavelength $\lambda_{0} ; K_{i}$ is the range-independent constant; $O_{i}(R)$ is the overlap function; $\beta\left(R, \lambda_{i}\right)=N_{i}(R) \sigma_{i}(\lambda)$ is backscatter coefficient for each species, where $N_{i}(R)$ is the number density and $\sigma_{i}(\lambda)$ is the Raman backscatter cross section at the Raman-shifted wavelength; $\alpha$ is the total extinction coefficient at wavelength $\lambda_{0}$, $\lambda_{\mathrm{N}_{2}}$ and $\lambda_{\mathrm{H}_{2} \mathrm{O}}$; and $r$ is the range considered as an integration variable.

The water vapour mixing ratio is defined as the ratio of the mass of water vapour to the mass of dry air in a sample of the atmosphere (Goldsmith et al., 1998). We can obtain the ratio $N_{\mathrm{H}_{2} \mathrm{O}}(R) / N_{\mathrm{N}_{2}}(R)$ that is proportional to the water vapour mixing ratio $(w)$ from Eq. (1) (Guerrero-Rascado et al., 2008). Assuming identical overlap factors and rangeindependent Raman backscatter cross sections for the two signals this ratio can be expressed as

$$
\begin{aligned}
\frac{N_{\mathrm{H}_{2} \mathrm{O}}(R)}{N_{\mathrm{N}_{2}}(R)}= & \frac{P\left(R, \lambda_{\mathrm{H}_{2} \mathrm{O}}\right)}{P\left(R, \lambda_{\mathrm{N}_{2}}\right)} \frac{K_{\mathrm{N}_{2}} \sigma_{\mathrm{N}_{2}}}{K_{\mathrm{H}_{2} \mathrm{O}} \sigma_{\mathrm{H}_{2} \mathrm{O}}} \\
& \exp \left\{\int_{0}^{R}\left[\alpha\left(r, \lambda_{\mathrm{H}_{2} \mathrm{O}}\right)-\alpha\left(r, \lambda_{\mathrm{N}_{2}}\right)\right] \mathrm{d} r\right\}
\end{aligned}
$$

and thus

$$
\begin{aligned}
w(R) & =\frac{P\left(R, \lambda_{\mathrm{H}_{2} \mathrm{O}}\right)}{P\left(R, \lambda_{\mathrm{N}_{2}}\right)} K \\
& \exp \left\{\int_{0}^{R}\left[\alpha\left(r, \lambda_{\mathrm{H}_{2} \mathrm{O}}\right)-\alpha\left(r, \lambda_{\mathrm{N}_{2}}\right)\right] \mathrm{d} r\right\},
\end{aligned}
$$

where $K$ takes into account the fractional volume of nitrogen in the atmosphere $(78.08 \%)$, the ratio of molecular masses, the range-independent calibration constants $K_{\mathrm{N}_{2}}$ and $K_{\mathrm{H}_{2} \mathrm{O}}$, and range-independent Raman backscatter cross sections $\sigma_{\mathrm{N}_{2}}$ and $\sigma_{\mathrm{H}_{2} \mathrm{O}}$. The assumption of identical overlap for nitrogen and water vapour is not true in real applications and differences between both overlap functions are found in the near range. Whiteman et al. (2006) found errors around $6 \%$ at an altitude of $300 \mathrm{~m}$ above the lidar system. To avoid any incomplete overlap we have not used the near range for the water vapour calibration.

In summary, the water vapour mixing ratio profile is obtained by the ratio of water vapour lidar signal to nitrogen lidar signal, a constant calibration factor and an exponential correction due to the difference in extinction between the nitrogen shifted and water vapour shifted wavelength. This exponential can be evaluated for Rayleigh scattering by using radiosonde or standard atmospheric profiles of temperature and pressure while the particle contribution can be neglected in most cases (Mattis et al., 2002). Considering only Rayleigh scattering, the exponential term deviates by less than $3 \%$ from unity for most atmospheric conditions found in our station.

\subsection{Raman lidar water vapour calibration}

As has been shown in the previous section, profiles of water vapour mixing ratio are computed from the ratio of Raman water vapour to Raman nitrogen return signals. Whiteman et al. (1992) showed that a single calibration constant can be used to convert these lidar signal ratios into water vapour mixing ratios expressed as the mass of water vapour divided by the mass of dry air. Calibration of water vapour Raman lidar measurements has been extensively discussed in the past (Vaughan et al., 1988; Whiteman, 2003; Leblanc et al., 2008). There are three main approaches for obtaining this calibration constant. One approach requires accurate knowledge of the optical transmission characteristics of the lidar system and the ratio of Raman scattering cross sections between water vapour and nitrogen. Leblanc et al. (2012) found that the precision of this approach to compute calibration values is rarely better than $10 \%$. Because of the difficulty in reducing the uncertainties in the Raman cross sections and in determining the optical transmission characteristics of the entire lidar detection system, other alternative approaches have been developed (Ferrare et al., 1995; Leblanc et al., 2012). A second approach consists of estimating the constant $\mathrm{K}$ lidar signal ratios using one (or a set of) well-known water vapour mixing ratio profile(s) measured independently. Radiosonde measurement in the troposphere is the reference and most common technique used today. The third common calibration procedure is based on the comparison of total precipitable water (TPW) obtained through the vertical integration of the water vapour profiles obtained with the Raman lidar and the TPW retrieved from a co-located GPS or microwave radiometer. When using an external measurement, the accuracy of the calibration procedure for the Raman system follows that of the measurement used as reference. Today 

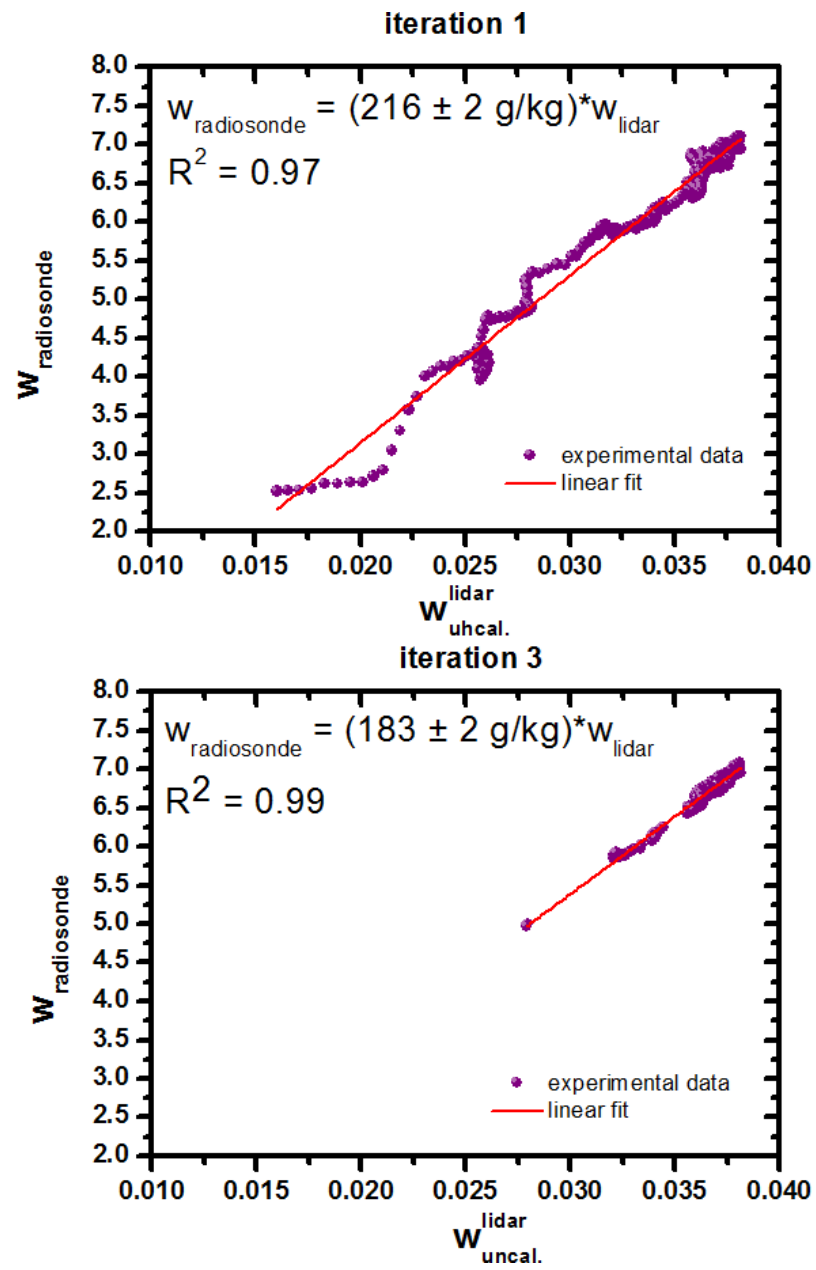

Fig. 1. Iterative procedure of linear regressions to retrieve lidar calibration constant from the comparison of lidar and radiosonde data: (top) regression for the first iteration, (bottom) final regression (iteration 3).

the accuracy of the best quality radiosondes, GPS and microwave measurements is estimated to be $5 \%, 7 \%$ and $10 \%$ respectively (Miloshevich et al., 2004; Leblanc et al., 2012).

In this work the second approach has been adopted whereby lidar profiles are compared with simultaneous and co-located radiosonde measurements of water vapour. Radiosounding campaigns were performed at our station during Summer and Autumn 2011. As already mentioned, a total of 12 GRAW DFM-09 radiosondes (six at midday and six at night) were launched simultaneously with lidar measurements.

Only the six radiosondes launched at night-time were appropriate for the calibration of the water vapour Raman channel. The radiosonde data were vertically interpolated in order to obtain an equivalent $7.5 \mathrm{~m}$ resolution to match the lidar resolution. For calibration purpose, a conventional least square regression was performed between the lidar and radiosonde data. Lidar data between 1.5 and $4.0 \mathrm{~km}$ (a.s.1.)
Table 1. Linear fit between lidar and co-located radiosondes measurements. Calibration of lidar water vapour profiles was obtained using data between 1.5 and $4.0 \mathrm{~km}$ (a.s.1.).

\begin{tabular}{llcc}
\hline Date & Slope & $R^{2}$ & SD \\
\hline 18 Jul 2011 & $183.7 \pm 0.1$ & 0.99 & 0.06 \\
22 Jul 2011 & $185.7 \pm 0.2$ & 0.99 & 0.05 \\
25 Jul 2011 & $183.1 \pm 0.1$ & 0.99 & 0.05 \\
28 Jul 2011 & $187.0 \pm 0.1$ & 0.99 & 0.13 \\
17 Nov 2011 & $182.2 \pm 0.2$ & 0.99 & 0.03 \\
24 Nov 2011 & $192.4 \pm 0.1$ & 0.99 & 0.08 \\
\hline
\end{tabular}

were used in the calibration regression. This range was chosen in order to assure a region with high water vapour mixing ratio (minimizing the error in radiosonde data) and to avoid the large differences that could be found between lidar and radiosonde measurements at higher heights due to radiosonde drift and the incomplete lidar overlap in the near field.

A robust iterative procedure is presented here in order to find the best least-squares regression. For this purpose after the initial fitting, the standard deviation of the data points around the regression line is computed. A scan is then made through the data points, eliminating all points that deviate from the regression line by more than one standard deviation. The remaining points are used for a new least-squares regression. These steps are repeated until the linear regression slope changes by less than $1 \%$. If the number of remaining points is less than $50 \%$ of the initial number the calibration will not be considered as valid. An example of this iterative procedure, corresponding to 25 June 2011, is shown in Fig. 1. Three iterations were needed to achieve slope convergence. The figure shows only the first (Fig. 1, top) and the last (Fig. 1, bottom) linear regression. Note that for this case data points deleted after this filtering procedure correspond to low values of water vapour mixing ratio, where radiosondes present larger errors (Ferrare et al., 1995). It can be observed that for the last iteration (\#3) the coefficient of determination $\left(R^{2}\right)$ significantly increases. In this case, the calibration constant reaches a value of $183 \pm 2 \mathrm{~g} \mathrm{~kg}^{-1}$.

For all cases used in the calibration procedure the number of iterations was less than five with good agreement among calibration constants computed for different dates. Table 1 shows the final slope (corresponding to the calibration constant), $R^{2}$ and standard deviations for the six nights used in the calibration of the lidar water vapour channel.

A mean value of $186 \pm 4 \mathrm{~g} \mathrm{~kg}^{-1}$ was obtained as the calibration coefficient for the whole campaign. The standard deviation for the mean calibration coefficient was close to $2 \%$. Previous studies have shown similar standard deviations. Thus, using 15 lidar-radiosonde comparisons at IFT, Leipzig (Germany), the calibration coefficient was computed with a standard deviation of around $5 \%$ (Mattis et al., 2002). 
A similar value was obtained using 31 Vaisala RS-80 radiosondes for calibrating the NASA Goddard Space Flight Center Scanning Raman Lidar with the same technique during the CAMEX-3 campaign (Whiteman, 2003). Therefore, the calibration constant obtained in this work presents a better uncertainty than those reported in other works.

Figure 2 shows water vapour mixing ratio profiles obtained from the Raman lidar profiles using the mean calibration constant calculated above, together with the profiles obtained from radiosondes. The two examples presented correspond to 22 and 25 July 2011, which show different amount of water vapour. A good agreement between lidar and radiosonde profiles was observed at all altitudes. Absolute deviations were lower than $0.4 \mathrm{~g} \mathrm{~kg}^{-1}$ at altitudes below $5.5 \mathrm{~km}$ (a.s.l.) on 25 July, while on 22 July larger deviations were found in the range $2.5-3.5 \mathrm{~km}$ (a.s.l.) where the mean absolute deviation reached $1 \mathrm{~g} \mathrm{~kg}^{-1}$. These results confirm the capability of Raman lidar systems to provide accurate measurements of water vapour mixing ratio in the lower troposphere.

A statistical analysis in terms of mean absolute deviations and standard deviations between lidar and radiosonde water vapour mixing ratio profiles is presented in Table 2. This table shows the discrepancies observed at different heights between 1.5 and $5.5 \mathrm{~km}$ (a.s.l.), with surface level at $0.68 \mathrm{~km}$ (a.s.1.). The mean absolute deviations have been plotted (Fig. 3) in order to illustrate better the dependency of these values with altitude. The mean absolute deviation is below $0.5 \mathrm{~g} \mathrm{~kg}^{-1}$ for $55 \%$ of the selected ranges. We can observe that the largest discrepancies are found between 4.5 and $5.5 \mathrm{~km}$ (a.s.1.), reaching a maximum mean absolute deviation of $2.2 \mathrm{~g} \mathrm{~kg}^{-1}$ on 17 November. Inspection of the RCS temporal evolution reveals that clouds were present at this height range during this night. On 28 July and 24 November an important loss of verticality in the radiosonde was observed at $5 \mathrm{~km}$ (a.s.l.). At this altitude the horizontal distance from the radiosonde to lidar station were 6.6 and $9 \mathrm{~km}$ respectively. The loss of verticality and the atmospheric inhomogeneities could explain the differences in water vapour observed between the lidar and radiosondes. Anyway, the mean absolute deviation for the whole profile including the six dates was $0.6 \pm 0.6 \mathrm{~g} \mathrm{~kg}^{-1}$, thus indicating a good agreement in the water vapour mixing ratio retrieved by both techniques.

\subsection{Retrieval of relative humidity using Raman lidar and temperature from microwave radiometer}

In this section a new approach to retrieve relative humidity profiles from the combination of Raman lidar and microwave radiometer measurements is discussed. Relative humidity (RH) is an important variable in the description of aerosolcloud interaction and hygroscopic growth studies (Fan et al., 2007). Global radiosonde observations provide most of the RH information required as input in weather-forecast models. But as has been indicated, the temporal resolution of routine observations performed by weather services is rather
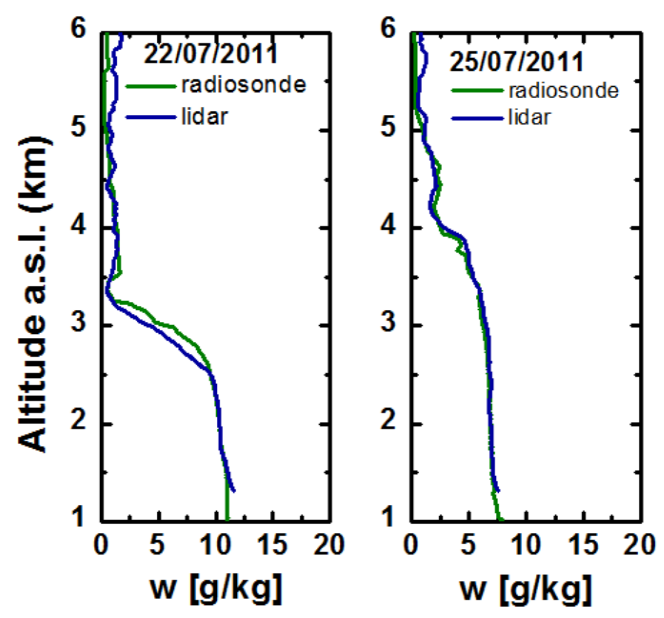

Fig. 2. Water vapour mixing ratio profiles from radiosonde and Raman lidar during night-time on (left) 22 July and (right) 25 July, 2011.

low, typically with one or two radiosonde launches per day. Therefore important weather phenomena such as the development of the convective boundary layer and the passage of cold and warm fronts are not appropriately monitored (Mattis et al., 2002).

On the other hand, the use of Raman lidars for the acquisition of information on aerosol and water vapour, which permits the study of the same air volume, is a powerful and attractive approach to study aerosol-climate interactions, because the optical properties of particles strongly depend on RH (Navas-Guzmán et al., 2013). At present, the rotational Raman lidar technology allows simultaneous measurements of temperature and water vapour mixing ratio profiles to retrieve RH profiles (Brocard et al., 2013; Mattis et al., 2002; Reichardt et al., 2012; Ristori et al., 2005). The main problem is that the use of such systems is not widespread and most common lidar systems only provide water vapour mixing ratio profiles. This section presents $\mathrm{RH}$ profiles obtained from the combination of two instruments, a microwave radiometer and a Raman lidar. As already described, the Raman lidar technique is a powerful tool to retrieve mixing ratio profiles with a good vertical resolution during night-time. This information, combined with simultaneous temperature profiles from a co-located microwave radiometer, allows us to obtain RH profiles.

$\mathrm{RH}$ is defined as the ratio of the actual amount of water vapour in the air compared to the equilibrium amount (saturation) at that temperature (Rogers, 1979), and it can be calculated as

$\mathrm{RH}(z)=\frac{e(z)}{e_{w}(z)} \times 100$,

where $e(z)$ is the water vapour pressure and $e_{w}(z)$ is the saturation pressure. The water vapour pressure is related to the 
Table 2. Mean absolute deviation (mean $\delta$ ) and standard deviation (SD) of water vapour mixing ratio $\left(\mathrm{g} \mathrm{kg}^{-1}\right)$ between lidar and radiosonde data at different layers.

\begin{tabular}{lrrrrrrrrr}
\hline Date & \multicolumn{2}{c}{$1.5-2.5 \mathrm{~km}$} & \multicolumn{2}{c}{$2.5-3.5 \mathrm{~km}$} & \multicolumn{2}{c}{$3.5-4.5 \mathrm{~km}$} & \multicolumn{2}{c}{$4.5-5.5 \mathrm{~km}$} \\
\hline & mean $\delta$ & SD & mean $\delta$ & SD & mean $\delta$ & SD & mean $\delta$ & SD \\
\hline 18 Jul 2011 & 0.3 & 0.5 & 0.2 & 0.3 & 0.17 & 0.1 & 0.25 & 0.19 \\
22 Jul 2011 & 0.06 & 0.04 & 1.0 & 0.7 & 0.23 & 0.18 & 0.5 & 0.3 \\
25 Jul 2011 & 0.08 & 0.06 & 0.17 & 0.09 & 0.39 & 0.22 & 0.29 & 0.16 \\
28 Jul 2011 & 0.25 & 0.12 & 0.7 & 1.1 & 0.4 & 0.3 & 1.8 & 0.8 \\
17 Nov 2011 & 0.18 & 0.21 & 0.27 & 0.18 & 1.4 & 0.5 & 2.2 & 0.9 \\
24 Nov 2011 & 0.22 & 0.15 & 0.29 & 0.19 & 0.8 & 0.6 & 1.9 & 1.2 \\
\hline
\end{tabular}

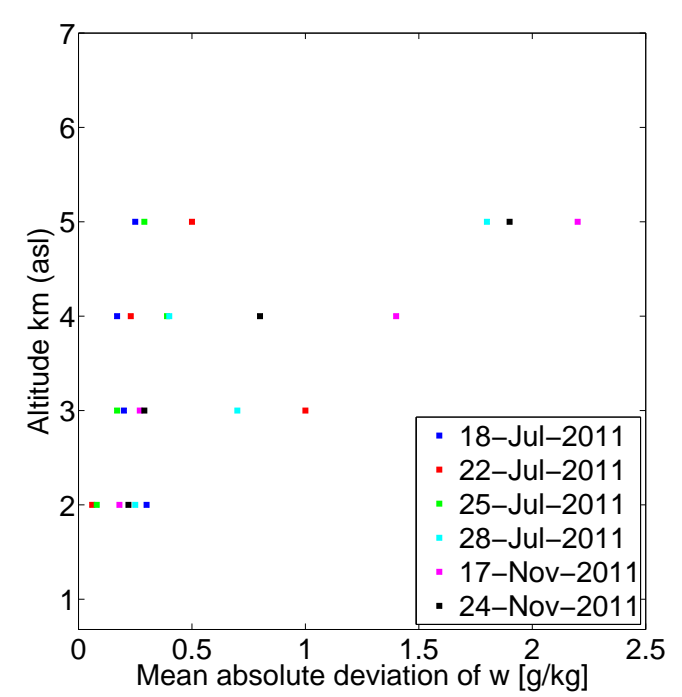

Fig. 3. Mean absolute deviation of water vapour mixing ratio between lidar and radiosondes.

water vapour mixing ratio as follows:

$e(z)=\frac{p(z) w(z)}{0.622+w(z)}$,

where $p(z)$ is the air pressure which must be estimated from profiles of routine radiosonde measurements or assuming standard atmospheric conditions. The use of an air pressure profile assuming a standard atmosphere (US 1976) scaled to a surface value measured at ground level in Eq. (5) leads to negligible errors in the computation of the water vapour pressure; therefore it will be used here. On the other hand, RH depends on temperature as a function of the saturation vapour pressure according to

$e_{w}(z)=6.107 \exp \left[\frac{M_{A}[T(z)-273]}{M_{B}+[T(z)-273]}\right]$

with the constants $M_{A}=17.84$ (17.08) and $M_{B}=245.4$ (234.2) for $T$ below (above) $273 \mathrm{~K}$ (List, 1951).

Figure 4 shows an example comparison between RH profiles retrieved from combination of a Raman lidar and a microwave radiometer and the corresponding radiosonde. The figure also shows the water vapour mixing ratio profiles retrieved from lidar and radiosonde (Fig. 4a) and the temperature profiles obtained from the radiosonde and the microwave radiometer (Fig. 4b). The results correspond to night-time measurements performed on 25 July 2011. The radiosonde was launched at 20:40 UTC and microwave radiometer and Raman lidar measurements were operating from 20:30 to 21:30 UTC. A water vapour mixing ratio profile from the Raman lidar was computed following the procedure described in the methodology. There was a very good agreement between the water vapour mixing ratio retrieved from lidar and radiosonde (Fig. 4a). Differences were lower than $5 \%$ below $3.5 \mathrm{~km}$ a.s.l. although they slightly increase (up to $8 \%$ ) above this height. In Fig. 4c, the RH profile (red line) was computed using the water vapour mixing ratio profile (Fig. 4a) from lidar and the temperature profile from microwave radiometer (Fig. 4b) as previously described. The profile shows a good agreement when compared with the RH profile retrieved from radiosonde. The largest discrepancies are found around $3.4 \mathrm{~km}$ (a.s.1.), where radiosonde $\mathrm{RH}$ values are around $15 \%$ larger than those retrieved from the Raman lidar and the microwave radiometer. These larger differences in $\mathrm{RH}$ are due to the deviation between the temperature measured with the radiosonde and those retrieved from the microwave radiometer (Fig. 4b). Discrepancies between both temperatures profiles reached maximum values of $30 \%$ at these heights. However, the agreement in the rest of the RH profiles is quite good, with relative differences below $10 \%$.

RH profiles have also been obtained for the rest of the nights with coincident radiosondes, therefore a total of six profiles were retrieved. A statistical analysis for the temperature and RH variables has been performed for these cases. Table 3 shows the mean absolute deviation between temperatures obtained from the microwave radiometer and from the radiosondes at different height ranges. A mean absolute deviation of $1.2 \pm 0.7 \mathrm{~K}$ is found for the whole column $(0-5 \mathrm{~km}$, a.g.l.). It can be seen that the absolute deviation of the temperature is lower than $1.0 \mathrm{~K}$ for the height range below $2 \mathrm{~km}$ (a.g.l.). It can be observed that discrepancies increase with altitude, reaching a maximum value of $2.1 \pm 1.5 \mathrm{~K}$ between 4 and $5 \mathrm{~km}$ (a.g.1.). This increase in temperature deviations 

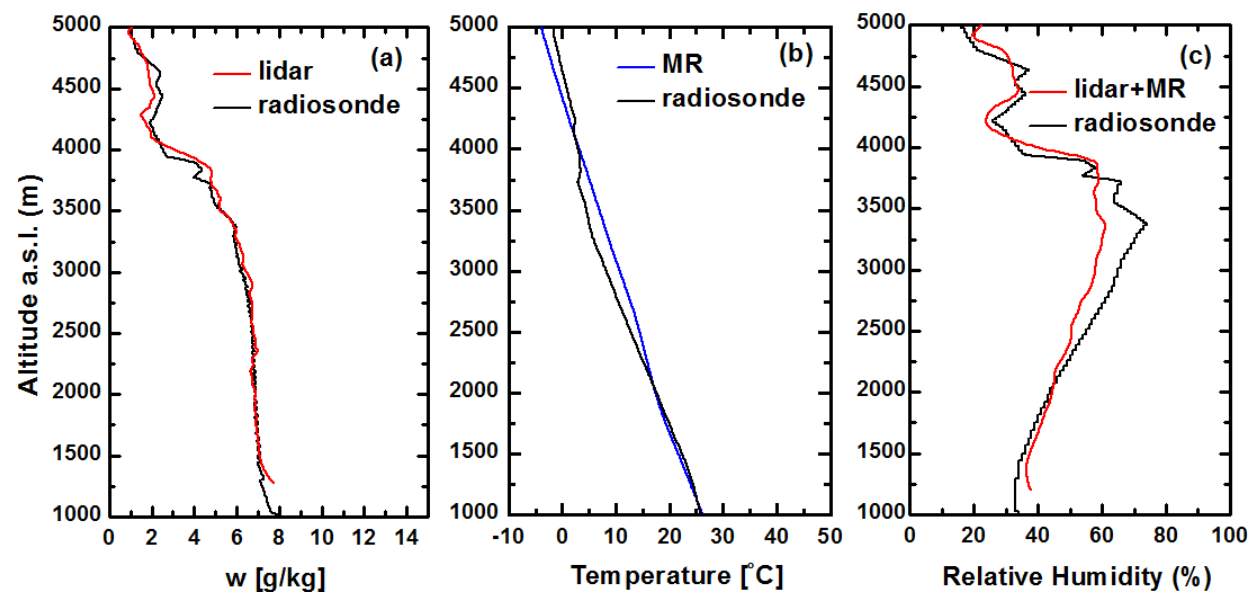

Fig. 4. Night-time measurements performed on 25 July 2011. (a) Water vapour mixing ratio profiles retrieved from Raman lidar and radiosonde, (b) temperature profiles from microwave radiometer and radiosonde, and (c) RH profile obtained from Raman lidar and microwave radiometer (MR) and from radiosonde.

Table 3. Mean absolute deviation (mean $\delta$ ) for temperature and relative humidity profiles for the six experiments at different altitude ranges.

\begin{tabular}{llll}
\hline range $[\mathrm{km}]$ & mean $\delta(T)[\mathrm{K}]$ & range $[\mathrm{km}]$ & mean $\delta(\mathrm{RH})[\%]$ \\
\hline $0-1$ & $0.3 \pm 0.1$ & $0.5-1$ & $3.1 \pm 1.4$ \\
$1-2$ & $0.8 \pm 0.1$ & $1-2$ & $4.9 \pm 2.2$ \\
$2-3$ & $1.4 \pm 0.8$ & $2-3$ & $6 \pm 3$ \\
$3-4$ & $1.5 \pm 1.1$ & $3-4$ & $5.4 \pm 2.2$ \\
$4-5$ & $2.1 \pm 1.5$ & $4-5$ & $19 \pm 12$ \\
\hline
\end{tabular}

with altitude could be explained by the loss of verticality in the radiosonde data due to wind drift. Moreover, the lower vertical resolution of microwave radiometer in the far height range is also responsible for larger errors in this region. In fact, the largest deviations are found for those regions where there is a strong gradient in the temperature profile (e.g. inversions) since the microwave radiometer vertical resolution produces some artificial smoothing in the profile.

Table 3 also shows the absolute deviation between the RH profiles retrieved for both methodologies. The range selected for the comparison was $0.5-5 \mathrm{~km}$ (a.g.l.). The first $0.5 \mathrm{~km}$ closest to the surface has not been taken into account in order to avoid the potential non-cancellation of the overlap functions for the nitrogen and water vapour channels. The mean absolute deviation in the RH between 0.5 and $5 \mathrm{~km}$ (a.g.l.) was $7 \pm 6 \%$. The RH deviations change with altitude in a way similar to the temperature deviations. A loss of verticality of the radiosonde and the lower resolution of the microwave radiometer in the far height range could again explain these discrepancies. Nevertheless, a low mean absolute deviations (below $6 \%$ in $\mathrm{RH}$ ) for $\mathrm{RH}$ profiles between 0.5 and $4 \mathrm{~km}$ (a.g.1.) is observed. Measurements of RH profiles presented here are very useful for the analysis of hygroscopic

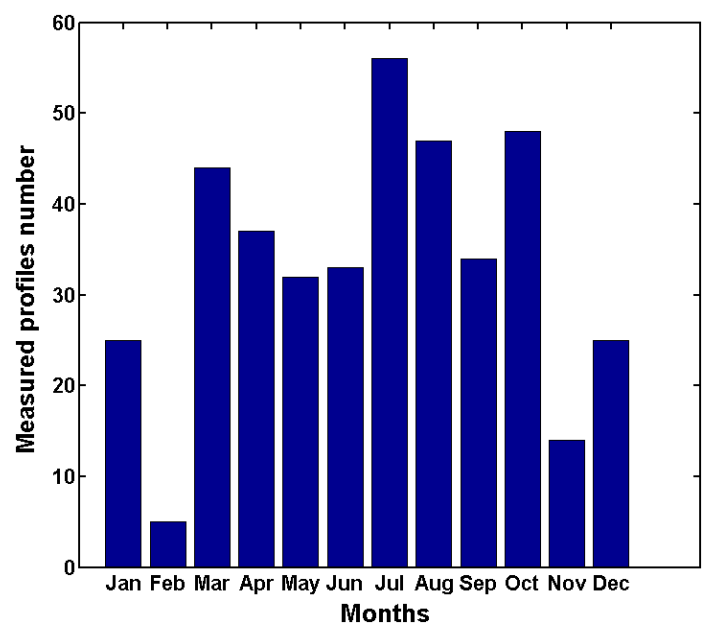

Fig. 5. Monthly distribution of water vapour profiles in 2011.

growth based on Raman lidar and microwave radiometer measurements. The combination of these RH profiles with aerosol optical data retrieved with the lidar system allows us to obtain hygroscopic growth factors for different aerosol types (Di Girolamo et al., 2012; Veselovskii et al., 2009). In addition, this methodology allows the possibility of obtaining RH profile measurements with higher frequency than radiosoundings and simultaneously to lidar measurements. However, the accuracy needs to be improved to obtain accurate values of the hygroscopic growth factors. In particular, it is necessary to improve the vertical resolution of the temperature profiles to reduce the uncertainties. 

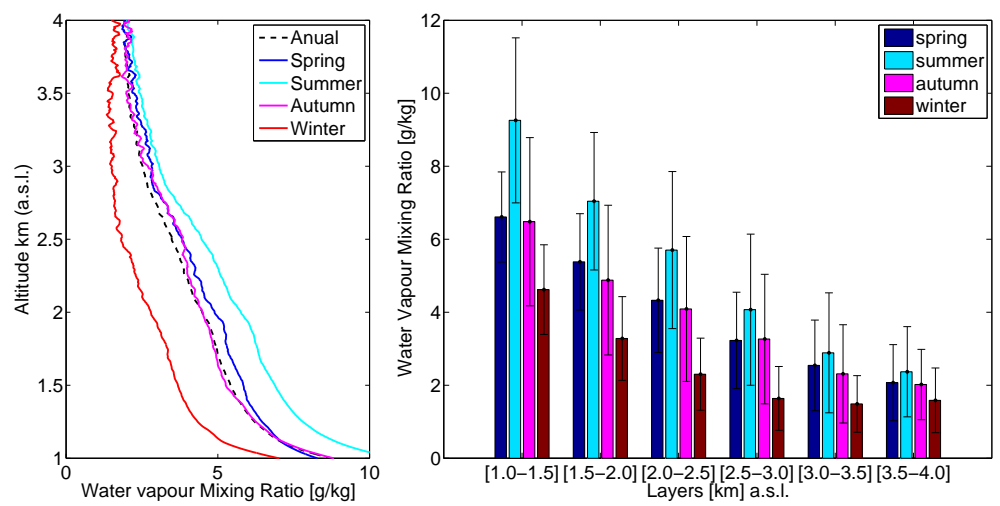

Fig. 6. Seasonal vertical profiles (left) and seasonal mean values for different layers (right) of water vapour mixing ratio. The error bars indicate the standard deviation.

\section{Statistical analysis of water vapour properties}

A 1-year data set has been selected in order to obtain a statistical analysis of water vapour mixing ratio and relative humidity profiles. The chosen period extends from 1 January to 31 December of 2011. During this year a total of 400 lidar inversions were successfully obtained from nighttime measurements. The time resolution of these lidar profiles was $30 \mathrm{~min}$. Figure 5 shows the monthly distribution of the inverted profiles. We can observe that a rather low number of profiles were retrieved during February and November, mainly due to the presence of low clouds and rain.

Mean seasonal vertical profiles of $w$ have been calculated from the Raman lidar measurements during night-time (Fig. 6a). This figure shows mean profiles for the range 1$4 \mathrm{~km}$ (a.s.1.). A clear seasonal behaviour is observed from this plot. The largest values are observed in summer for the whole range while the lowest values were found in winter. Spring and autumn presented values very similar although were slightly larger in spring in the lower part of the troposphere. The largest values of $w$ found in summer could be due to the greater evapotranspiration (sum of evaporation and plant transpiration) from the earth's land surface to atmosphere in this season. Figure $6 \mathrm{~b}$ presents the seasonal mean values obtained for different layers of $500 \mathrm{~m}$. The error bars presented in this plot indicate the standard deviation. Despite the large standard deviations presented in some cases a clear seasonal behaviour was again observed for the different layers. The $w$ values showed a clear decrease with the altitude ranged from values close $9 \mathrm{~g} \mathrm{~kg}^{-1}$ in the lowest layers (Summer) up to values close to $2 \mathrm{~g} \mathrm{~kg}^{-1}$ at the highest layers (Winter).

A statistical study of $\mathrm{RH}$ profiles was also performed for this year of measurements. The RH profiles were retrieved from $w$ and $T$ profiles as explained in the previous section. Figure 7 shows the seasonal mean values of RH for different layers $(500 \mathrm{~m})$. For this property a clear anti-correlation with the behaviour of $w$ profiles is found. The largest RH

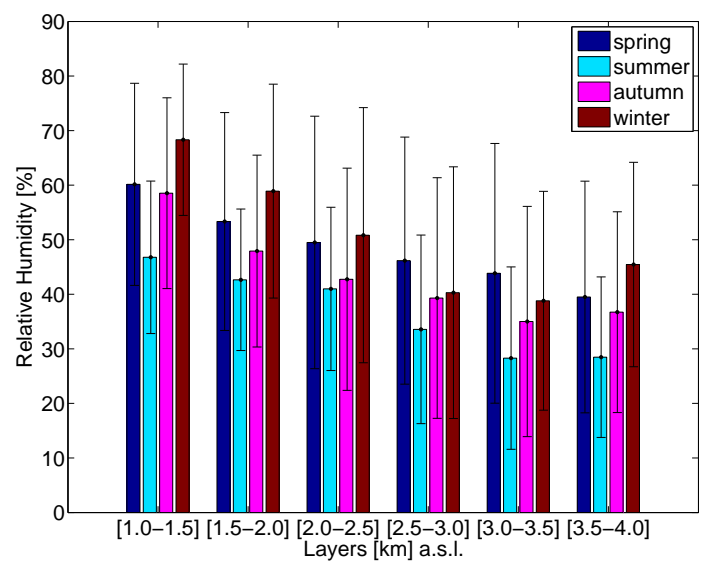

Fig. 7. Seasonal mean values of RH for different layers. The error bars indicated the standard deviation.

values are found in winter while the lowest values are found in summer in most of the layers. This anti-correlation is due to the strong dependence of this property with the temperature. The lower temperatures found in winter favour being closer of saturation conditions, therefore the $\mathrm{RH}$ values are higher in this season. Moreover, this plot also shows a clear decrease of the RH values with altitude.

Finally Fig. 8 presents the RH value distribution obtained for $500 \mathrm{~m}$ layers between 1 and $4 \mathrm{~km}$ (a.s.1.). A total of 2379 layers were used in this analysis. From this distribution we observe that $60 \%$ of the layers presented $\mathrm{RH}$ values between 20 and $60 \%$. It can be seen that this was the most frequent situation and these values were found in all the seasons and at all altitudes. Despite this, an important number of layers ( $25 \%$ of the total) reached values larger than $60 \%$. Aerosols exposed to these high humidities could change their chemical, physical and optical properties due to their increased water content. Therefore, this RH statistic could be helpful for future hygroscopic studies. 


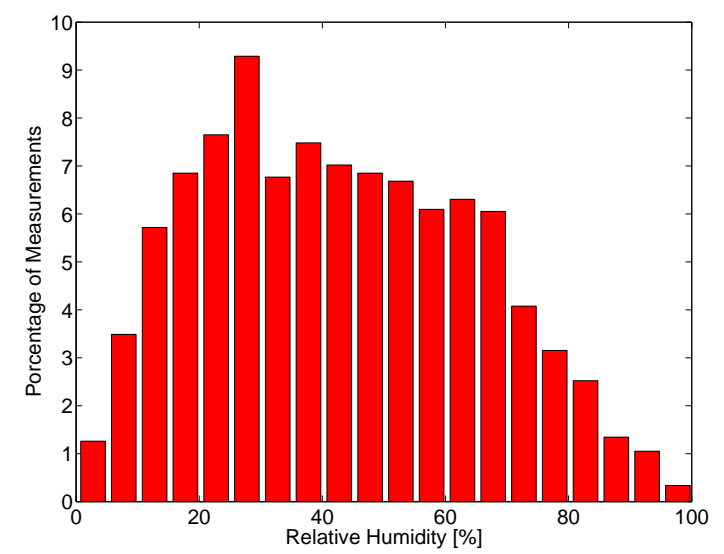

Fig. 8. RH distribution obtained from $500 \mathrm{~m}$ layers for 1 year of measurements

\section{Conclusions}

This study has presented water vapour measurements performed with Raman lidar and radiosondes during nighttime at Granada. First, the methodology for obtaining water vapour mixing ratio profiles from Raman lidar was presented. A radiosonde field campaign was performed in order to retrieve the calibration constant for the lidar water vapour channel. Linear regression between the lidar and radiosonde data at the range $1.5-4.0 \mathrm{~km}$ (a.s.1.) was used to retrieve this constant. A robust iterative approach to obtain the best calibration constant was introduced. A mean value of $186 \pm 4 \mathrm{~g} \mathrm{~kg}^{-1}$ was obtained as the calibration coefficient for the whole campaign. The standard deviations in the calibration coefficient were found to be close to $2 \%$. Good agreement between radiosonde- and lidar-derived profiles was achieved. The mean absolute deviation between the lidar and sounding data was about $0.6 \pm 0.6 \mathrm{~g} \mathrm{~kg}^{-1}$ in the altitude range $1.5-5.5 \mathrm{~km}$ (a.s.1.). These results confirm the capability of Raman lidar systems to provide accurate measurements of water vapour mixing ratio in the lower troposphere.

Moreover, water vapour mixing ratio profiles retrieved from Raman lidar combined with temperature profiles from a microwave radiometer made it possible to obtain RH profiles. A statistical analysis in terms of mean absolute deviation of these profiles with those obtained from radiosondes found that the mean absolute deviation for the temperature in the lower troposphere $(0-5 \mathrm{~km}$, a.g.1. $)$ is around $1.2 \pm 0.7^{\circ} \mathrm{C}$. The discrepancies in the RH were found to be around $7 \pm 6 \%$. The errors were smaller (below $1.0^{\circ} \mathrm{C}$ in the temperature and $5 \%$ in the $\mathrm{RH}$ ) for the first two kilometres of the atmosphere. This study show the capability of obtaining accurate $\mathrm{RH}$ profiles from the combination of Raman lidar and microwave radiometer measurements. It will be very useful for future hygroscopic growth studies.

In the last part of this work a statistical study of water vapour properties has been presented. A total of 400 lidar profiles retrieved in 2011 together with microwave measurements were used to retrieve $w$ and RH profiles. Mean seasonal vertical profiles of $w$ showed that the largest values are found in summer when a greater evapotranspiration from the earth's land surface to atmosphere exists. The lowest values were found in winter. This properties showed a clear decrease with the altitude for all seasons. The analysis of the RH profiles showed a clear anti-correlation with the observed behaviour of the $w$, with larger values in winter and lower in summer. An analysis of RH values found for layers of $500 \mathrm{~m}$ showed that the $60 \%$ of them were between 20 and $60 \%$; $25 \%$ of these layers presented values larger than $60 \%$ and therefore are potential cases of aerosol hygroscopic growth. This study evidences the capability of remote sensing techniques to characterize water vapour with a high spatial and temporal resolution in the lower troposphere.

Acknowledgements. This work was supported by the Andalusian Regional Government through projects P12-RNM-2409 and P10-RNM-6299, by the Spanish Ministry of Science and Technology through projects CGL2010-18782, CSD2007-00067, CGL2011-13580-E/CLI and CGL2011-16124-E; and by the EU through the ACTRIS project (EU INFRA-2010-1.1.16-262254).

Edited by: G. Ehret

\section{References}

Alados-Arboledas, L., Müller, D., Guerrero-Rascado, J., NavasGuzmán, F., Pérez-Ramírez, D., and Olmo, F.: Optical and microphysical properties of fresh biomass burning aerosol retrieved by Raman lidar, and star-and sun-photometry, Geophys. Res. Lett., 38, L01807, doi:10.1029/2010GL045999, 2011.

Brocard, E., Philipona, R., Haefele, A., Romanens, G., Mueller, A., Ruffieux, D., Simeonov, V., and Calpini, B.: Raman Lidar for Meteorological Observations, RALMO - Part 2: Validation of water vapor measurements, Atmos. Meas. Tech., 6, 1347-1358, doi:10.5194/amt-6-1347-2013, 2013.

Bösenberg, J., Matthias, V., Amodeo, A., Amoiridis, V., Ansmann, A., Baldasano, J., Balin, I., Balis, D., Bockmann, C., Boselli, A., Carlsson, G., Chaikovsky, A., Chourdakis, G., Comeron, A., De Tomasi, F., Eixmann, R., Freudenthaler, V., Giehl, H., Grigorov, I., Hagard, A., Iarlori, M., Kirsche, A., Kolarov, G., Komguem, L., Kreipl, S., Kumpf, W., Larcheveque, G., Linne, H., Matthey, R., Mattis, I., Mekler, A., Mironova, I., Mitev, V., Mona, L., Müller, D., Music, S., Nickovic, S., Pandolfi, M., Papayannis, A., Pappalardo, G., Pelon, J., Perez, C., Perrone, R. M., Persson, R., Resendes, D. P., Rizi, V., Rocadenbosch, F., Rodrigues, J. A., Sauvage, L., Schneidenbach, L., Schumacher, R., Shcherbakov, V., Simeonov, V., Sobolewski, P., Spinelli, N., Stachlewska, I., Stoyanov, D., Trickl, T., Tsaknakis, G., Vaughan, G., Wandinger, U., Wang, X., Wiegner, M., Zavrtanik, M., and Zerefos, C.: EARLINET: A European Aerosol Research Lidar Network to establish an aerosol climatology, Max-Planck-Institut für Meteorologie, 2003.

De Tomasi, F. and Perrone, M.: Lidar measurements of tropospheric water vapor and aerosol profiles over southeastern Italy, J. 
Geophys. Res.-Atmos., 108, 4286, doi:10.1029/2002JD002781, 2003.

Di Girolamo, P., Summa, D., Bhawar, R., Di Iorio, T., Cacciani, M., Veselovskii, I., Dubovik, O., and Kolgotin, A.: Raman lidar observations of a Saharan dust outbreak event: characterization of the dust optical properties and determination of particle size and microphysical parameters, Atmos. Environ., 50, 66-78, 2012.

Fan, J., Zhang, R., Li, G., and Tao, W.-K.: Effects of aerosols and relative humidity on cumulus clouds, J. Geophys. Res.-Atmos., 112, D14204, doi:10.1029/2006JD008136, 2007.

Ferrare, R., Melfi, S., Whiteman, D., Evans, K., Schmidlin, F., and Starr, D. O.: A comparison of water vapor measurements made by Raman lidar and radiosondes, J. Atmos. Ocean. Tech., 12, 1177-1195, 1995.

Ferrare, R., Ismail, S., Browell, E., Brackett, V., Clayton, M., Kooi, S., Melfi, S., Whiteman, D., Schwemmer, G., Evans, K., Russell, P., Livingston, J., Schmid, B., Holben, B., Remer, L., Smirnov, A., and Hobbs, P. V.: Comparison of aerosol optical properties and water vapor among ground and airborne lidars and Sun photometers during TARFOX, J. Geophys. Res.-Atmos., 105, $9917-$ 9933, 2000.

Goldsmith, J., Blair, F. H., Bisson, S. E., and Turner, D. D.: Turnkey Raman lidar for profiling atmospheric water vapor, clouds, and aerosols, Appl. Optics, 37, 4979-4990, 1998.

Granados-Muñoz, M., Navas-Guzmán, F., Bravo-Aranda, J., Guerrero-Rascado, J., Lyamani, H., Fernández-Gálvez, J., and Alados-Arboledas, L.: Automatic determination of the planetary boundary layer height using lidar: One-year analysis over southeastern Spain, J. Geophys. Res.-Atmos., 117, D18208, doi:10.1029/2012JD017524, 2012.

Guerrero-Rascado, J., Ruiz, B., Chourdakis, G., Georgoussis, G., and Alados-Arboledas, L.: One year of water vapour Raman lidar measurements at the Andalusian Centre for Environmental Studies (CEAMA), Int. J. Remote Sens., 29, 5437-5453, 2008.

Guerrero-Rascado, J. L., Olmo, F. J., Avilés-Rodríguez, I., NavasGuzmán, F., Pérez-Ramírez, D., Lyamani, H., and Alados Arboledas, L.: Extreme Saharan dust event over the southern Iberian Peninsula in september 2007: active and passive remote sensing from surface and satellite, Atmos. Chem. Phys., 9, 84538469, doi:10.5194/acp-9-8453-2009, 2009.

Guerrero-Rascado, J. L., Costa, M. J., Bortoli, D., Silva, A. M., Lyamani, H., and Alados-Arboledas, L.: Infrared lidar overlap function: an experimental determination, Opt. Express, 18, 2035020359, 2010.

Haefele, A., Hocke, K., Kämpfer, N., Keckhut, P., Marchand, M., Bekki, S., Morel, B., Egorova, T., and Rozanov, E.: Diurnal changes in middle atmospheric $\mathrm{H}_{2} \mathrm{O}$ and $\mathrm{O}_{3}$ : Observations in the Alpine region and climate models, J. Geophys. Res.-Atmos., 113, D17303, doi:10.1029/2008JD009892, 2008.

Han, Y., Snider, J., Westwater, E., Melfi, S., and Ferrare, R.: Observations of water vapor by ground-based microwave radiometers and Raman lidar, J. Geophys. Res., 99, 695-18, 1994.

Held, I. M. and Soden, B. J.: Water Vapor Feedback and Global Warming 1, Annu. Rev. Energ. Env., 25, 441-475, 2000.

Ismail, S. and Browell, E. V.: Recent lidar technology developments and their influence on measurements of tropospheric water vapor, J. Atmos. Ocean. Tech., 11, 76-84, 1994.

Kiehl, J. and Trenberth, K. E.: Earth's annual global mean energy budget, B. Am. Meteorol. Soc., 78, 197-208, 1997.
Leblanc, T., McDermid, I. S., and Aspey, R. A.: First-year operation of a new water vapor Raman lidar at the JPL Table Mountain Facility, California, J. Atmos. Ocean. Tech., 25, 1454-1462, 2008.

Leblanc, T., McDermid, I. S., and Walsh, T. D.: Ground-based water vapor raman lidar measurements up to the upper troposphere and lower stratosphere for long-term monitoring, Atmos. Meas. Tech., 5, 17-36, doi:10.5194/amt-5-17-2012, 2012.

List, R. J.: f\& Smithsonian meteorological Tables, 6th rev. Edn., compiled by: Robert, J., List. Washington, D.C., Smithsonian Inst., 527 pp., 1951.

Mattis, I., Ansmann, A., Althausen, D., Jaenisch, V., Wandinger, U., Müller, D., Arshinov, Y. F., Bobrovnikov, S. M., and Serikov, I. B.: Relative-humidity profiling in the troposphere with a Raman lidar, Appl. Optics, 41, 6451-6462, 2002.

Miloshevich, L. M., Paukkunen, A., Vömel, H., and Oltmans, S. J.: Development and validation of a time-lag correction for Vaisala radiosonde humidity measurements, J. Atmos. Ocean. Tech., 21, 1305-1327, 2004.

Navas-Guzmán, F., Rascado, J. G., and Arboledas, L. A.: Retrieval of the lidar overlap function using Raman signals, Opt. Pura Apl, 44, 71-75, 2011.

Navas-Guzmán, F., Müller, D., Bravo-Aranda, J., GuerreroRascado, J., Granados-Muñoz, M., Pérez-Ramírez, D., Olmo, F., and Alados-Arboledas, L.: Eruption of the Eyjafjallajökull Volcano in spring 2010: Multiwavelength Raman lidar measurements of sulphate particles in the lower troposphere, J. Geophys. Res.-Atmos., 118, 1804-1813, 2013.

Pérez-Ramírez, D., Navas-Guzmán, F., Lyamani, H., FernándezGálvez, J., Olmo, F., and Alados-Arboledas, L.: Retrievals of precipitable water vapor using star photometry: Assessment with Raman lidar and link to sun photometry, J. Geophys. Res.Atmos., 117, D05202, doi:10.1029/2011JD016450, 2012.

Reichardt, J., Wandinger, U., Serwazi, M., and Weitkamp, C.: Combined Raman lidar for aerosol, ozone, and moisture measurements, Opt. Eng., 35, 1457-1465, 1996.

Reichardt, J., Wandinger, U., Klein, V., Mattis, I., Hilber, B., and Begbie, R.: RAMSES: German Meteorological Service autonomous Raman lidar for water vapor, temperature, aerosol, and cloud measurements, Appl. Opt., 51, 8111-8131, 2012.

Ristori, P., Froidevaux, M., Dinoev, T., Serikov, I., Simeonov, V., Parlange, M., and Van den Bergh, H.: Development of a temperature and water vapor Raman LIDAR for turbulent observations, in: Remote Sensing, 59840F-59840F, International Society for Optics and Photonics, 2005.

Rogers, R. R.: A Short Course in Cloud Physics, A short course in cloud physics, Elmsford (NY, USA): Pergamon Press, 227 pp., 1979.

Rose, T., Crewell, S., Löhnert, U., and Simmer, C.: A network suitable microwave radiometer for operational monitoring of the cloudy atmosphere, Atmos. Res., 75, 183-200, 2005.

Scheiben, D., Schanz, A., Tschanz, B., and Kämpfer, N.: Diurnal variations in middle-atmospheric water vapor by ground-based microwave radiometry, Atmos. Chem. Phys., 13, 6877-6886, doi:10.5194/acp-13-6877-2013, 2013.

Vaughan, G., Wareing, D., Thomas, L., and Mitev, V.: Humidity measurements in the free troposphere using Raman backscatter, Q. J. Roy. Meteorol. Soc., 114, 1471-1484, 1988.

Veselovskii, I., Whiteman, D., Kolgotin, A., Andrews, E., and Korenskii, M.: Demonstration of Aerosol Property Profil- 
ing by Multiwavelength Lidar under Varying Relative $\mathrm{Hu}-$ midity Conditions, J. Atmos. Ocean. Tech., 26, 1543-1557, doi:10.1175/2009JTECHA1254.1, 2009.

Wandinger, U. and Ansmann, A.: Experimental determination of the lidar overlap profile with Raman lidar, Appl. Optics, 41, 511$514,2002$.
Whiteman, D. N.: Examination of the traditional Raman lidar technique. II. Evaluating the ratios for water vapor and aerosols, Appl. Optics, 42, 2593-2608, 2003.

Whiteman, D., Melfi, S., and Ferrare, R.: Raman lidar system for the measurement of water vapor and aerosols in the Earth's atmosphere, Appl. Optics, 31, 3068-3082, 1992. 